\title{
Pathogenicity characteristics of an Iranian variant-2 (IS-1494) like infectious bronchitis virus in experimentally infected SPF chickens
}

\author{
H. NAJAFI ${ }^{1}$, A. GHALYANCHI LANGEROUDI ${ }^{1}$, M. HASHEMZADEH $^{2 *}$, O. MADADGAR ${ }^{1}$, V. KARIMI $^{3}$, \\ R. K. FARAHANI ${ }^{4}$, H. ABDOLLAHI ${ }^{4}$, H. MAGHSOUDSLOO ${ }^{4}$, P. SEIFOURI ${ }^{4}$
}

\begin{abstract}
${ }^{1}$ Department of Microbiology and Immunology, Faculty of Veterinary Medicine, University of Tehran, Tehran, Iran; ${ }^{2}$ Department of Research and Production of Poultry Viral Vaccine, Razi Vaccine and Serum Research Institute, Karaj, Iran; ${ }^{3}$ Department of Clinical Sciences, Faculty of Veterinary Medicine, University of Tehran, Tehran, Iran; ${ }^{4}$ Iranian Veterinary Organization, Tehran, Iran
\end{abstract}

Received January 11, 2016; revised May 11, 2016; accepted November 10, 2016

\begin{abstract}
Summary. - Avian infectious bronchitis (IB) is a major cause of economic loss to the poultry industry. IB virus primarily affects respiratory tract, but strains differ in their tropism for such other target organs as kidneys and alimentary tract. The objective of this study was to estimate the pathogenicity of an Iranian IB virus (IBV) variant (variant-2) which is one of the most prevalent isolates circulating in Iranian poultry farms. SPF chickens were intranasally inoculated with $10^{4} \mathrm{EID}_{50} / 0.1 \mathrm{ml}$ of the virus. Sera, fecal swabs, and different tissue samples were collected on different days post infection. Clinical signs, gross pathology, and histological changes were recorded. The amount of virus genome was quantified in different tissues and feces using quantitative real-time PCR assay. The highest viral loads were detected in the feces and cecal tonsils. Real-time PCR results demonstrated variant- 2 tropism for respiratory tract, digestive system and renal tissue that is due to its epitheliotropic nature. This is the first pathogenicity study of Iranian variant-2 virus. Based on histology observations and clinical signs this isolate was classified as a nephropathogenic IBV. Further knowledge of IBV pathogenesis permits to perform more effective prevention practice.
\end{abstract}

Keywords: avian infectious bronchitis; Iran; pathogenesis; nephropathogen; histopathology

\section{Introduction}

Avian infectious bronchitis (IB) is an acute and highly contagious disease of chickens. The etiologic agent, IB virus (IBV), belongs to the genus Gammacoronavirus within the Coronaviridae family. The name of the disease refers to its most frequent clinical manifestation, although it can infect many other epithelial cells, including the kidney, genital organs and many parts of the alimentary tract (Jackwood and De Wit, 2013). The disease is characterized by respiratory signs including gasping, coughing, sneezing, tracheal rales

*Corresponding author: E-mail: mhashemzadeh15@gmail.com; phone: $+98-2634570038$.

Abbreviations: $\mathrm{IB}=$ infectious bronchitis; IBV = IB virus; p.i. = post inoculation; $\mathrm{EID}_{50}=$ embryo infective dose and nasal discharge. The virus causes decilliation and desquamation of the tracheal epithelium. Some strains of the virus cause severe kidney damage, urolithiasis and may be associated with high mortality (Liu et al., 2008). Outbreaks of the disease can occur even in vaccinated flocks because there is slight or no cross-protection among serotypes (Mohammed et al., 2012). The first isolation of IBV from Iranian chicken flocks was reported in 1994. Until recently, Massachusetts (Mass) and 793/B were the only IBV genotypes identified in Iran. New IBV genotypes including IS720, variant-2, QX, IR-I, and IR-II were detected in a molecular surveillance performed during 2010-2014 (Hosseini et al., 2015). Najafi et al. (2015) isolated and characterized variant-2, QX, IS720, IR-I, $793 / \mathrm{B}$, and Mass genotypes from tissue samples collected from Iranian broiler farms between the years 2014-2015. There is no information about the pathogenic aspects of these new variants. Regarding the high prevalence of variant- 2 
IBV in Iran, the present study was conducted to evaluate its pathogenicity and tissue tropism in experimentally 2 -weekold infected SPF chickens.

\section{Materials and Methods}

Strain history and virus titration. Tissue samples of the trachea and kidney were collected from broilers showing clinical signs suspected to be related to IB. Samples were taken from vaccinated flocks of eight provinces of Iran. For virus isolation, homogenized samples were inoculated into the allantoic cavity of 9-11-day-old SPF embryonated eggs. Primary diagnosis of IBV was done using a PCR assay with the target of 5'-UTR part of IBV genome. For genotyping, positive samples were submitted to a nested PCR reaction amplifying the $\mathrm{S} 1$ gene. Based on genotyping and molecular epidemiology results, the variant-2 virus was identified as a dominant isolate with the prevalence rate of $33.8 \%$ (40 from the total number of 118). From these forty, variant- 2 isolates, one was selected at the fifth egg passage level. It was shown to be free from contamination by other important avian pathogens (virus, bacteria and mycoplasma) using different PCR assays. EID ${ }_{50}$ was calculated by Reed-Muench method and the isolate was used in the experimental pathogenicity study.

Experimental design. 49 SPF one-day old chicks were randomly divided into two groups consisting of 35 chicks in the experimental and 14 in the control group. Each group was housed in a different isolator. At age of 14 days, birds in the experimental group were intranasally challenged with the allantoic fluid of variant-2 virus containing $10^{4} \mathrm{EID}_{50} / 0.1 \mathrm{ml}$ of the virus. On days $1,3,5,7,14,21$, and 28 post inoculation (p.i.), five chickens from experimental group and two chickens from control group were randomly selected, used for sample collection. Sera of birds were collected for ELISA. Gross lesions were recorded, and their trachea, lung, spleen, kidneys, proventriculus, cecal tonsils and cloacal swabs were aseptically collected for virus quantification using real time PCR assay.

Detection of anti-IBV antibodies. IBV antibody test kit, (polyclonal kit) ProFLOK IBV ELISA kit (Synbiotics, USA) was used for the detection of specific IBV antibodies in the serum samples according to manufacturer's instructions.

RNA Extraction and cDNA synthesis. RNA was extracted from tissue samples using Cinna Pure RNA kit (Sinaclone, Iran) following manufacturers' instructions. cDNA was generated using RevertAid first strand cDNA synthesis kit (Thermo Scientific).

Real-Time PCR assay. Real-time PCR assay, in order to amplify a conserved sequence within the 5 -untranslated region (UTR) of the IBV genome and $28 \mathrm{~S}$ ribosomal RNA (rRNA) as a reference gene, was used. A downstream primer (IBV5'GU391 5'-GCTTTTGAGCCTAGCGTT-3') located at nucleotide position 391-408 of the IBV M41 strain genome sequence; an upstream primer (IBV5'GL533 5'-GCCATGTTGTCACTGTCTATTG-3') located at nucleotide position 512-533 of the IBV M41 strain ge- nome sequence and a Taqman ${ }^{\circledR}$ dual-labeled probe (IBV5'G probe 5'-FAMCACCACCAGAACCTGTCACCTC-BHQ1-3') located at nucleotide position 473-494 were designed to amplify a $143 \mathrm{bp}$ fragment of 5'-UTR (Callison et al., 2006). For 28S rRNA gene, forward primer (28S F 5'-GGCGAAGCCAGAGGAAACT-3'), reverse primer (28S R 5'-GACGACCGATTTGCACGTC-3') and probe (FAM-AGGACCGCTACGGACCTCCACCATAMRA) were used to amplify a $61 \mathrm{bp}$ fragment (Rothwell et al., 2004). PCR products for 5 -UTR and $28 \mathrm{~S}$ rRNA were ligated into pTG19-T vector and transformed to Escherichia coli TOP10 competent cells. Plasmids were extracted by MBST Plasmid isolation kit minipreparation (MBST, Iran). Plasmid concentrations were determined by spectrophotometry (picodrop) and serial dilutions were performed to give a final concentrations between $10^{2}$ and $10^{5}$ (5'-UTR) or $10^{2}$ and $10^{5}$ (28S rRNA) copies. The $20 \mu \mathrm{l}$ real-time PCR reaction contained $2 \mu \mathrm{l}$ of 10x PCR Buffer (Sinaclon), $1 \mu \mathrm{l}$ of dNTP mix (Sinaclon), $0.8 \mu \mathrm{MgCl}_{2}$ (50 mmol/1; Sinaclon), 0.2 $\mu \mathrm{l}$ of CinnaGen Taq DNA polymerase (Sinaclon), $5 \mu$ l of template cDNA, primers to a final concentration of $0.1 \mu \mathrm{mol} / \mathrm{l}$ and probe to a final concentration of $0.1 \mu \mathrm{mol} / \mathrm{l}$. The reaction was carried out in a QIAGEN Rotor-Gene Q (Corbett Rotor Gene 6000). PCR cycling parameters were $95^{\circ} \mathrm{C}$ for $2 \mathrm{~min}$, then 40 cycles of $95^{\circ} \mathrm{C}$ for $15 \mathrm{sec}$ and $60^{\circ} \mathrm{C}$ for $1 \mathrm{~min}$.

Histopathological examination. Specimens from the trachea, lung, and kidney were placed in 10\% buffered formalin, sectioned, stained with haematoxylin and eosin, and evaluated for histological lesions.

\section{Results}

\section{Clinical sings, gross lesion and mortality}

Clinical disease was visible from day 5 p.i. with the highest severity on 14 day p.i. At day 5 p.i., chickens showed depression, ruffled feathers, nasal discharge and coughing. Mild watery diarrhea was noted in some chicks from day 7. Chickens in infected group showed small amount of catarrhal exudate in the trachea with slight mucosal hyperaemia between day 3 to 7 p.i. From day 5 to 14 p.i., kidneys from almost all infected birds were moderately enlarged and swollen. No clinical signs and gross lesions were observed in control group of chickens. No mortality occurred during experiment.

\section{Serological results}

The serum from chickens of infected and control groups were tested for IBV antibody levels. In the infected group, serum was negative during days $1,3,5,7$, and 14 p.i., but they gave positive results 21 and 28 days p.i. with the titers of 437 and 554, respectively. Sera from control group were negative. 


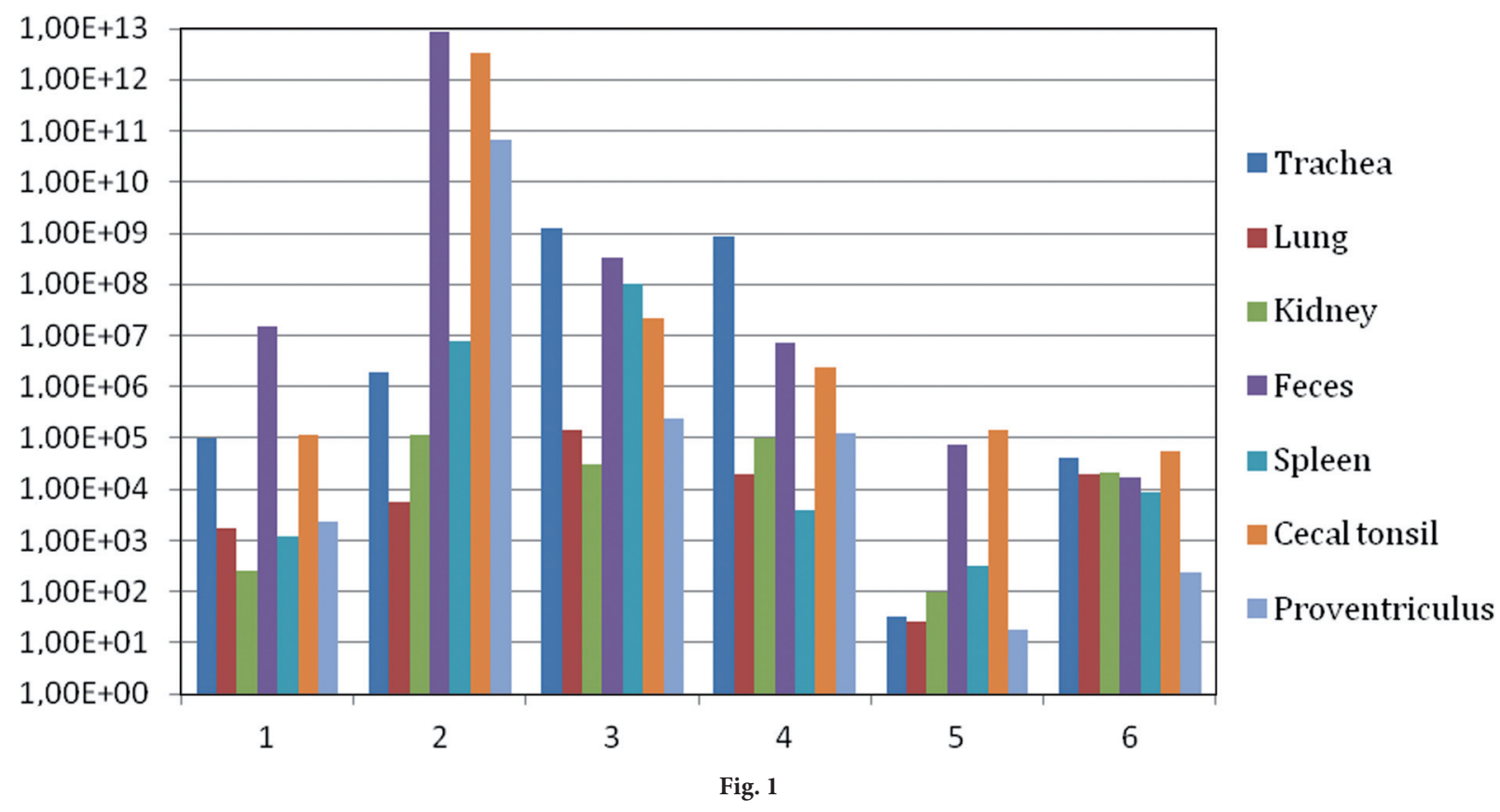

Viral relative load obtained in a quantitative real-time PCR assay on days 1, 3, 5, 7, 14, and 21 p.i. from different tissue samples and the feces of SPF chicks infected with Iranian variant-2 infectious bronchitis virus isolate
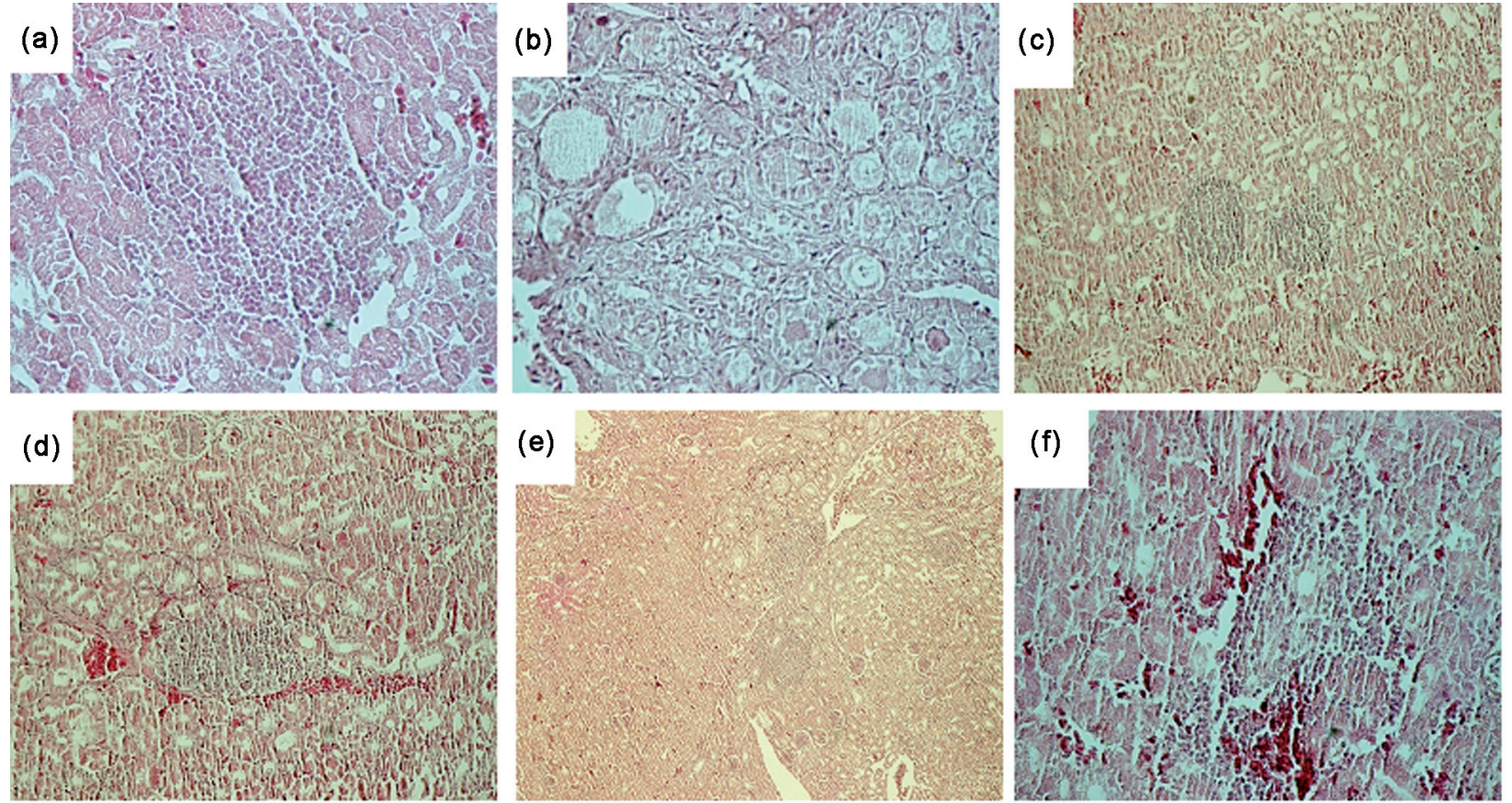

Fig. 2

Microscopic changes of the kidney tissue samples at days 1 (a), 3 (b), 5 (c), 7 (d), 14 (e), and 21 (f) p.i. in the SPF chicks infected with Iranian variant-2 infectious bronchitis virus isolate

(a) focal mononuclear cell infiltration in the interstitium; (b) hyperemia, necrosis of tubular epithelium, infiltration of eosinophils in ureters and casts in tubules; (c) hyperemia, vacuolation and necrosis of tubular epithelium, lymphoplasmacytic nodules formation in the interstitium; (d) and (e) lymphoplasmacytic nodules in the interstitium; (f) focal infiltration of mononuclear cells and haemorrhage. 


\section{Real-time PCR results}

The highest viral amount could be measured at day 3 p.i. in the feces and cecal tonsils. In the kidney and proventriculus the loads culminated at day 3 p.i., while in the trachea, lung and spleen the virus reached the highest load on day 5 p.i. Viral loads detected in the feces and cecal tonsils were the highest, the preventriculus, trachea, spleen, kidney and lung followed, respectively. The virus persisted until the last day of experiment in all tissues and feces (Fig. 1).

\section{Histopathological findings}

Microscopical lesions were observed in the kidneys from day 1 p.i. including focal mononuclear cell infiltration in the interstitium. Hyperemia, necrosis of tubular epithelium, infiltration of eosinophils in the ureters and casts in tubules were observed from day 3 p.i. Main lesions in the kidney introducing interstitial nephritis including vacuolation and necrosis of tubular epithelium occurred on day 5 p.i. Lymphoplasmacytic nodules in the interstitium appeared at day 5 and lasted until day 14 . From day 14 to 21 p.i. renal interstitial hemorrhage and slight lymphocytic infiltrates were recorded (Fig. 2). In the tracheas, loss of cilia, epithelial degeneration and slight infiltration of inflammatory cells in lamina propria were found at day 5 p.i., progressing to severe mononuclear infiltration on day 7. From day 14 p.i., mild mononuclear infiltration in lamina propria was recorded (Fig. 3). In the lungs, hyperemia, mild mononuclear infiltration in parenchyma and desquamation of bronchial epithelium were observed on day 5 p.i., and lymphoid nodules in bronchial wall, emphysema and mononuclear cell infiltration were noted on day 7. Hyperemia and mild infiltrations of inflammatory cells were the only lesions found on days 14 and 21 p.i. (Fig. 4).

\section{Discussion}

Avian infectious bronchitis caused by the infectious bronchitis virus, is an acute and highly contagious disease of chickens (Jackwood and De Wit, 2013). Since the respiratory form of IB was first reported in the 1930s nephropathogenic (Albassam et al., 1986; Jackwood and De Wit, 2013) and enterotropic (Ambali and Jones, 1990) IBV strains, some with the affinity for the reproductive tract, have been reported (Jackwood and De Wit, 2013). In September 1996, an outbreak of disease, characterized mainly by swelling of the stomach, occurred in chicken flocks in Qingdao, China, designated QX IBV (Yu-
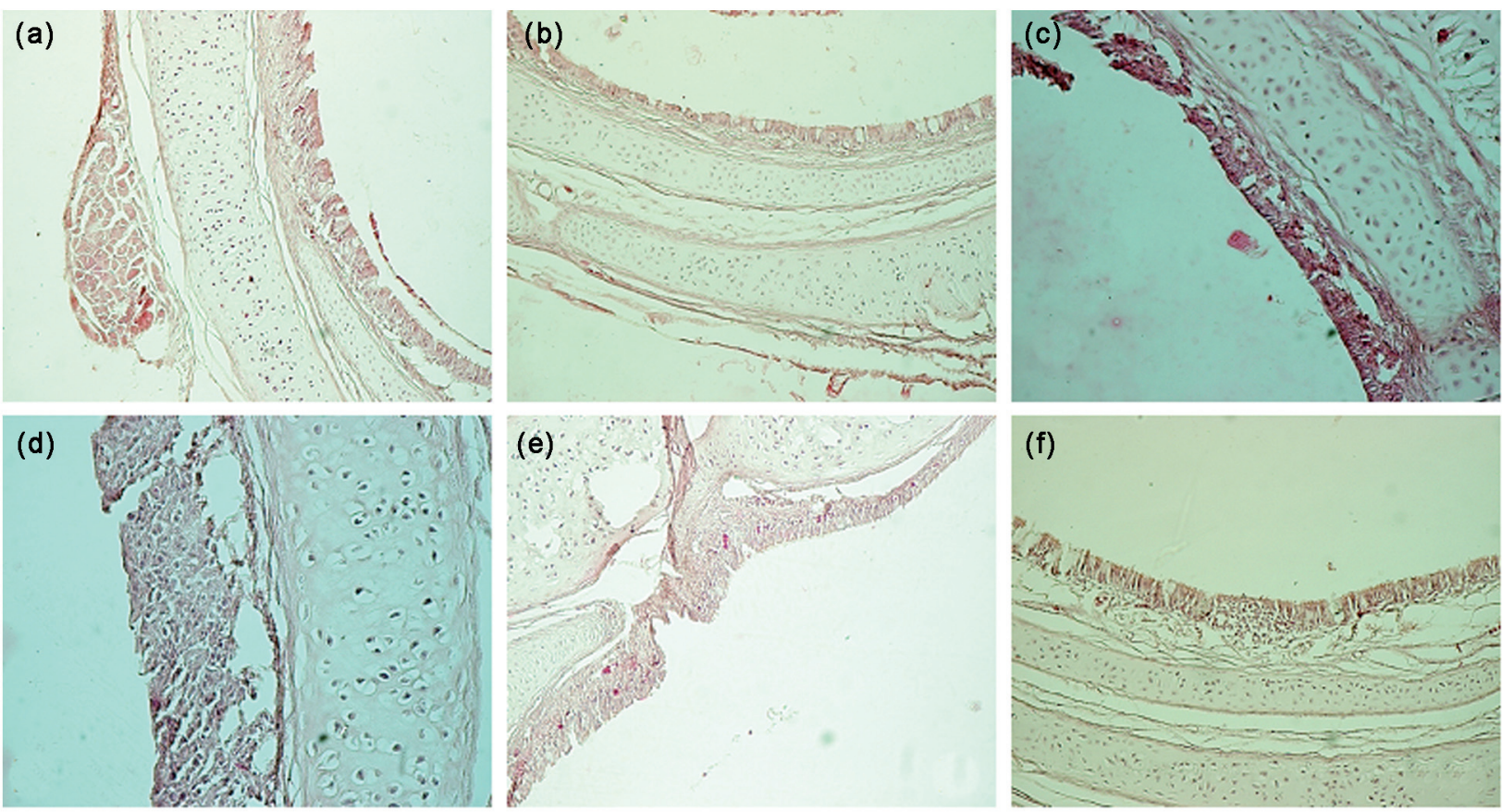

Fig. 3

Microscopic changes of the trachea tissue samples at days 1 (a), 3 (b), 5 (c), 7 (d), 14 (e), and 21 (f) p.i. in the SPF chicks infected with Iranian variant-2 infectious bronchitis virus isolate

(a) normal; (b) normal; (c) loss of cilia, epithelial degeneration, slight infiltration of inflammatory cells in lamina propria; (d) epithelial cell necrosis and severe mononuclear cell infiltration in lamina propria (e) slight mononuclear cell infiltration in lamina propria; (f) oedema and slight mononuclear cell infiltrate. 

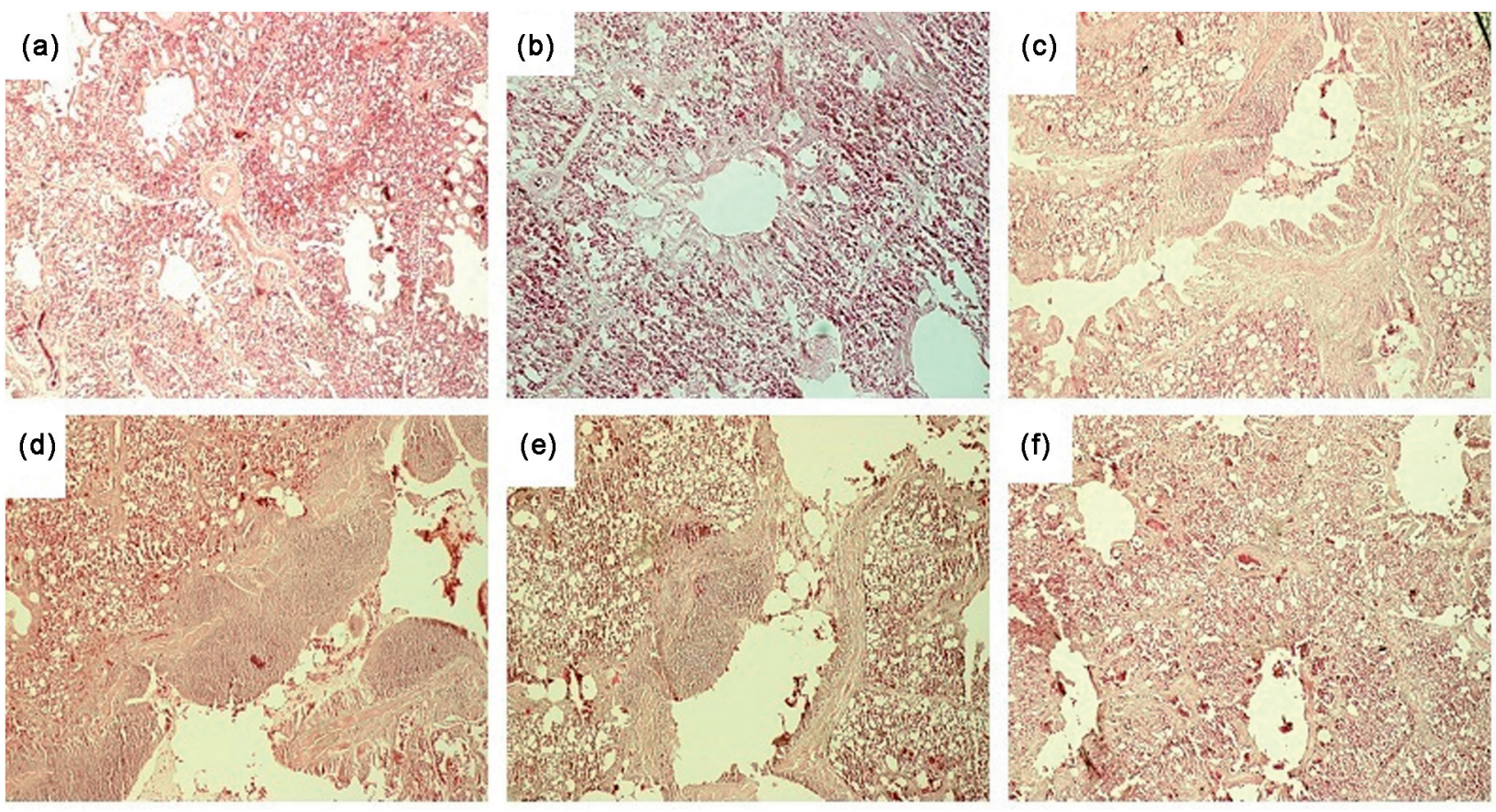

Fig. 4

Microscopic changes of the lung tissue samples at days 1 (a), 3 (b), 5 (c), 7 (d), 14 (e), and 21 (f) p.i. in the SPF chicks infected with Iranian variant-2 infectious bronchitis virus isolate

(a) and (b) bronchial hyperemia; (c) hyperemia, mild infiltration of mononuclear cells in parenchyma and desquamation of bronchial epithelium; (d) lymphoid aggregation in bronchial wall, mononuclear cell infiltration and emphysema; (e) mononuclear cell infiltration in interstitium and bronchial wall, (f) hyperemia and mild infiltration of inflammatory cells.

dong et al., 1998). The first outbreak of IBV in Iranian chicken flocks was reported in 1994. Outbreaks of 793/B serotype were subsequently reported by several researchers (Hashemzadeh et al., 2013; Seyfi Abad Shapouri et al., 2004; Shoushtari et al., 2008). In an epidemiology study of IBV between the years 2010-2014, seven distinct genotypes of Mass, 793/B, IS720, variant-2, QX, IR-I, and IR-II were identified (Hosseini et al., 2015). In years 2014-2015 genotypes variant-2, 4/91, IS/720, QX, IR-1 and Mass were isolated from broiler farms (Najafi et al., 2015). It was suggested in an experimental histological study that 793/B may be a nephropathogenic virus (Mahdavi et al., 2007; Boroomand et al., 2012). There is no information on the pathogenic traits of Iranian IBV genotypes. The present study was conducted to determine the pathogenesis, tissue tropism and pathological changes due to a variant- 2 virus. According to our results, the highest viral amount was detected in the faces, cecal tonsils and proventriculus on day 3 p.i. This finding may reflect the high viral affinity for the enteric tract, but it doesn't necessarily indicate its pathogenicity for the intestinal tract. Dolz et al. (2012), in a pathogenicity study of an Italy 02 serotype (which caused renal disease in young chicks) detected higher viral antigen rather in nasal turbinate than in kidneys. In a pathogenicity study of QX-like strains, higher viral loads were isolated in the trachea rather than in ovary and kidney (Benyeda et al., 2009). The high IB viral load in intestinal tract has been previously observed. IBV is shed via both the respiratory tract and the feces, and can persist in the birds and the intestinal tract for several weeks or months (De Wit et al., 2011). Lucio and Fabricant (1990) determined the tropism of three cloacal isolates and Massachusetts strain of IBV. Two cloacal isolates and M-41 were more frequently recovered from the cecal tonsils than from other tissues. Results confirmed that IBV, including M-41, can infect a variety of tissues and that some isolates may be recovered frequently from digestive tract tissues, particularly from the cecal tonsils (Lucio and Fabricant, 1990).

Massive replication of Italy 02 serotype (which was able to cause gross and microscopic lesions in kidney of 1 day old chicks) in enterocytes of cecal tonsil and rectum was observed (Dolz et al., 2012). In these locations, virus-specific staining was demonstrated as early as day 3 p.i. up to 24 days p.i. Benyeda et al. (2009) reported that the loads of QX-like strain culminated 7 days p.i. in the ileum and cecal tonsil and the virus was detectable in the cecal tonsil until 35 days p.i. In the group infected with M41, the highest load could be measured in the trachea and cecal tonsil. Chong and Apostolov (1982) in a study of pathogenesis of nephritis in chicks infected 
with Australian T strain of IBV noted there was no evidence of virus replication in the cecal tonsil and bursa of Fabricius but virus was readily recovered from the kidneys as well as feces of birds with acute and chronic nephritis (Chong and Apostolov, 1982). While the SAIBK nephropathogenic strain, H120 and M41 were detected for more than 28 days in the proventriculus (Fan et al., 2012). As our results show, the virus was detected in all tissues during all sampling days. Because of the epitheliotropic nature of virus, IBV with any kind of pathogenicity, has broad tissue distribution. Regarding this point and the fact that the IBV target organ does not necessarily show the highest viral load, the real time PCR results are not efficient enough to determine the pathogenic aspects of a microorganism. One group compared the pathogenicity of H120, M41 and SAIBK IBV strains using a quantitative real time RT-PCR followed by histology observations (Fan et al., 2012), another group used the viral nucleic acid detection in different tissues along with histological observations to assess the Italy 02 pathogenicity (Dolz et al., 2012). Benyeda et al. (2009) compared the pathogenicity of QX-like, M41 and 793/B IBV strains evaluating the ability of the strains to inhibit trachea epithelium ciliary activity, to induce immune response, to replicate and to cause histopathological lesions in designated organ. Immunofluorescent staining of the tracheal smears, ciliary activity, virus isolation and histopathology of the trachea was used to understand the pathogenesis of virulent and avirulent IBVs (Geilhausen et al., 1973). Clinical signs, gross and histological lesions and weight gain were considered as indicators to determine the pathogenicity of 5 IBV isolates from Ontario (Grgiæ et al., 2008).

In the present study the histological changes were observed in all three investigated organs. As it was reported previously, severe histologic lesions of respiratory tissues could be observed in nephropathogenic or QX-type IBV infections (Benyeda et al., 2009; Dolz et al., 2012; Purcell et al., 1976), but lesion indicative of interstitial nephritis could be found in the course of nephropathogenic IBV infections. The association of avian nephritis with IBV was initially reported from the US (Winterfield and Hitchner, 1962). However, nephritis associated with IBV was soon reported as a major problem in Australia (Cumming, 1963). More recently, increasing numbers of infections has been reported from other countries (Cook et al., 2001). Albassam et al. (1986) compared the nephropathogenicity of four IBV strains. All four strains produced acute renal changes consisting of tubular damage and interstitial inflammatory cell infiltration and edema. The Holte strain proved to be the least pathogenic, followed by the more pathogenic Gray and Italian strains and finally by the Australian strain. Pathogenicity of 25 strains of IBV isolated in Australia between 1961 and 1994 was compared. Twelve strains were nephropathogenic, and induced clinical nephritis, gross and histological kidney lesions, and mortality of 5-90\%. All strains, except one, induced histological renal lesions typical of interstitial nephritis (Ignjatovic et al., 2002).
Chen et al. studied histopathology and immunohistochemistry of renal lesions due to nephropathogenic IBV strain MA-87 which was isolated from kidneys of a broiler chicken in Japan. Lesions and viral antigen were first detected in the trachea and severe damage was afterwards observed in the kidney. Antigen-positive cells of ducts and tubules were degenerated and desquamated. The severe epithelial cell damage resulted in infiltration of heterophils and macrophages in the interstitium, ducts and tubules. The detection of viral antigen was consistent with the distribution of histological lesions at 6 to 8 days p.i. (Chen et al., 1996).

Considering the histopathological renal changes, variant- 2 can be classified as a nephropathogenic IBV. It is noteworthy that viruses of one genotype/serotype can have different cell tropisms and multiple pathological patterns, like the QX strain which was initially isolated in cases of proventriculitis. However, in subsequent studies, QX-type strains were recovered in cases associated with a drop in egg production and renal damage (Chacon et al., 2014). According to the high viral load in intestinal tract, and the study which was reported by Ambali and Jones whom did not find any microscopic lesions in the intestine of SPF birds after inoculation with an enterotropic strain, but demonstrated the high virus load in the trachea and in the tissues of the lower section of the gut and evidence of replication by immunostaining, variant- 2 may also cause enteric damage (Ambali and Jones, 1990). However to prove the enteropathogenicity of variant-2, the histological observations of different parts of intestinal tract are needed. This was the first pathogenicity study of Iranian variant-2 IBV which provided new insights on IBV pathogenesis. Further works to produce effective vaccines using the novel strains are needed.

Acknowledgement. This project was financially supported by research council of University of Tehran under grant No. 28692/6/1 and Iranian Veterinary Organization under grant No. 22/39007. The authors gratefully acknowledge Mr. Asadi for his extensive technical support. We would like to express our thanks to all those at the Iranian Veterinary Organization especially Dr.Tehrani and Dr.Hajakbari who helped to make this project.

\section{References}

Albassam M, Winterfield R, Thacker H (1986): Comparison of the nephropathogenicity of four strains of infectious bronchitis virus. Avian Dis. 30, 468-476. https:/doi. org $/ 10.2307 / 1590408$

AmbaliA, Jones R (1990): Early pathogenesis in chicks of infection with an enterotropic strain of infectious bronchitis virus. Avian Dis. 34, 809-817. https:/doi.org/10.2307/1591367

Benyeda Z, Mato T, Süveges T, Szabo E, Kardi V, Abonyi-Toth Z, Rusvai M, Palya V (2009): Comparison of the pathogenicity of QX-like, M41 and 793/B infectious bronchitis strains 
from different pathological conditions. Avian Pathol. 38, 449-456. https:/doi.org/10.1080/03079450903349196

Boroomand Z, Asasi K, Mohammadi A (2012): Pathogenesis and tissue distribution of avian infectious bronchitis virus isolate IRFIBV32 (793/B serotype) in experimentally infected broiler chickens. Scientific World J. 2012, 1-6.

Callison SA, Hilt DA, Boynton TO, Sample BF, Robison R, Swayne DE, Jackwood, MW (2006): Development and evaluation of a real-time Taqman RT-PCR assay for the detection of infectious bronchitis virus from infected chickens. J. Virol. Methods 138, 60-65.

Chacon J, Assayag Jr M, Revolledo L, Astolfi-Ferreira C, Vejarano M, Jones R, Piantino Ferreira A (2014): Pathogenicity and molecular characteristics of infectious bronchitis virus (IBV) strains isolated from broilers showing diarrhoea and respiratory disease. Br. Poult. Sci. 55, 271-283. https:/ doi.org/10.1080/00071668.2014.903558

Chen B, Hosi S, Nunoya T, Itakura C (1996): Histopathology and immunohistochemistry of renal lesions due to infectious bronchitis virus in chicks. Avian Pathol. 25, 269-283. https:/doi.org/10.1080/03079459608419141

Chong K, Apostolov K (1982): The pathogenesis of nephritis in chickens induced by infectious bronchitis virus. J. Comp. Pathol. 92, 199-211. https:/doi.org/10.1016/0021-9975(82)90078-0

Cook J, Chesher J, Baxendale W, Greenwood N, Huggins M, Orbell S (2001): Protection of chickens against renal damage caused by a nephropathogenic infectious bronchitis virus. Avian Pathol. 30, 423-426. https:/doi. org/10.1080/03079450120066421

Cumming R (1963): Infectious avian nephrosis (uraemia) in Australia. Aust. Vet. J. 39, 145-147. https:/doi.org/10.1111/ j.1751-0813.1963.tb04255.x

De Wit J, Cook JK, Van Der Heijden HM (2011): Infectious bronchitis virus variants: a review of the history, current situation and control measures. Avian Pathol. 40, 223-235. https:/ doi.org/10.1080/03079457.2011.566260

Dolz R, Vergara-Alert J, Perez M, Pujols J, Majo N (2012): New insights on infectious bronchitis virus pathogenesis: characterization of Italy 02 serotype in chicks and adult hens. Vet. Microbiol. 156, 256-264. https:/doi.org/10.1016/j.vetmic.2011.11.001

Fan W-q, Wang H-n, Zhang Y, Guan Z-b, Wang T, Xu C-w, Zhang A-y, Yang X (2012): Comparative dynamic distribution of avian infectious bronchitis virus M41, H120, and SAIBK strains by quantitative real-time RT-PCR in SPF chickens. Biosci. Biotechnol. Biochem. 76, 2255-2260. https:/doi. org/10.1271/bbb.120521

Geilhausen H, Ligon F, Lukert P (1973): The pathogenesis of virulent and avirulent avian infectious bronchitis virus. Arch. Virol. 40, 285-290. https:/doi.org/10.1007/bf01242547

Grgiæ H, Hunter DB, Hunton P, Nagy É (2008): Pathogenicity of infectious bronchitis virus isolates from Ontario chickens. Can. J. Vet. Res. 72, 403.

Hashemzadeh M, Karimi V, Masoudi S, Shoushtary A, Langeroudi A, Momayez R, Shirazi M, Maghsodloo H, Hasanzadeh R, Eshratabadi F (2013): Phylogenetic study of Iranian infectious bronchitis virus isolates during 2010-2011 using glycoprotein S1 gene. J. Vet. Res. 68, 135-141.
Hosseini H, Fard MHB, Charkhkar S, Morshed R (2015): Epidemiology of avian infectious bronchitis virus genotypes in Iran (2010-2014). Avian Dis. 59, 431-435. https:/doi. org/10.1637/11091-041515-ResNote.1

Ignjatovic J, Ashton D, Reece R, Scott P,Hooper P (2002): Pathogenicity of Australian strains of avian infectious bronchitis virus. J. Comp. Pathol. 126, 115-123. https:/doi. org/10.1053/jcpa.2001.0528

Jackwood MW, De Wit J (2013): Infectious Bronchitis. In DE Swayne (Ed.): Diseases of Poultry. Wiley-Blackwell, Ames, Iowa, pp. 139-153.

Liu S, Zhang X, Wang Y, Li C, Han Z, Shao Y, Li H, Kong X (2008): Molecular characterization and pathogenicity of infectious bronchitis coronaviruses: complicated evolution and epidemiology in china caused by cocirculation of multiple types of infectious bronchitis coronaviruses. Intervirology 52, 223-234. https:/doi.org/10.1159/000227134

Lucio B, Fabricant J (1990): Tissue tropism of three cloacal isolates and Massachusetts strain of infectious bronchitis virus. Avian Dis. 34, 865-870. https:/doi.org/10.2307/1591375

Mahdavi S, Tavasoly A, Pourbakhsh S, Momayez R (2007): Experimental histopathologic study of the lesions induced by serotype 793/B (4/91) infectious bronchitis virus. Arch. Razi 62, 15-22.

Mohammed M, Hair-Bejo M, Zahid AA-A, Alazawy A, Ahad EAA, Mauida FH (2012): Pathogenesis of Infectious bronchitis virus in infected broiler chickens. Avian Pathol. 37, 487-493.

Najafi H, Langeroudi AG, Hashemzadeh M, Karimi V, Madadgar O, Ghafouri SA, Maghsoudlo H, Farahani RK (2015): Molecular characterization of infectious bronchitis viruses isolated from broiler chicken farms in Iran, 2014-2015. Arch. Virol. 161, 53-62.

Purcell D, Tham V, Surman P (1976): The histopathology of infectious bronchitis in fowls infected with a nephrotropic "T" strain of virus. Aust. Vet. J. 52, 85-91. https:/doi. org/10.1111/j.1751-0813.1976.tb13864.x

Rothwell L, Young JR, Zoorob R, Whittaker CA, Hesketh P, Arche A, Smith AL, Kaiser P (2004): Cloning and characterization of chicken IL-10 and its role in the immune response to Eimeria maxima. J. Immunol. 173, 2675-2682. https:/ doi.org/10.4049/jimmunol.173.4.2675

Seyfi Abad Shapouri M, Mayahi M, Assasi K, Charkhkar S (2004): A survey of the prevalence of infectious bronchitis virus type 4/91 in Iran. Acta Vet. Hung. 52, 163-166. https:/ doi.org/10.1556/AVet.52.2004.2.4

Shoushtari A, Toroghi R, Momayez R, Pourbakhsh S (2008): 793/B type, the predominant circulating type of avian infectious bronchitis viruses 1999-2004 in Iran: a retrospective study. Arch. Razi 63, 1-5.

Winterfield R, Hitchner S (1962): Etiology of an infectious nephritis-nephrosis syndrome of chickens. Am. J. Vet. Res. 23, 1273.

Yudong W, YongLin W, Zichun Z, GenChe F, Yihai J, Xiange L, Jiang D, Shushuang, W (1998): Isolation and identification of glandular stomach type IBV (QX IBV) in chickens. Chin. J. Animal Quarantine 15, 1-3. 